BIOTROPIA No. 14, 1999: 17 - 35

\title{
THE OCCURRENCE OF INSECTS, FUNGI AND ORGANOLEPTIC CHARACTERISTICS IN STORED COFFEE BEANS IN LAMPUNG
}

\author{
OKKY S. DHARMAPUTRA, SUNJAYA, INA RETNOWATI and MUHAMMAD AMAD \\ SEAMED BIOTROP, P.O. Box 116, Bogor 16001, Indonesia \\ CAHYAISMAYADI \\ The Indonesian Research Institute for Coffee and Cocoa, \\ Jl. PB Sudirman 90, Jember 68118, Indonesia
}

\begin{abstract}
A survey on postharvest handling and technology processing of coffee beans at farmer, trader and exporter levels was conducted in West Lampung and Tanggamus regencies of Lampung province during harvest time (July 1998). Interviews and sampling of coffee beans were carried out during the survey. The number of respondents at farmer, trader and exporter levels was 22, 20 and 4, respectively, while the number of samples collected from each level was 20. All samples were analyzed for moisture content, physical quality, insect and fungal infestation, reducing sugar content, and coffee cupping.

The results of the interviews indicated that postharvest handling and technology processing became better from farmers to exporters.

Moisture contents of coffee beans collected from farmers and traders were higher than the tolerable limit recommended by SNI (13\%). Physical quality of coffee beans collected from exporters was higher than that collected from farmers and traders. Insects were found on coffee beans collected from farmers, traders and exporters, but the number of species and the percentage of samples infested by insects from each level were relatively low. The predominant species was Liposcelis entomophila. The number of fungal species on coffee beans collected from farmers was higher than that collected from traders and exporters. The predominant species at the three levels was Aspergillus niger, but the lowest percentage of beans infected by this fungus was found on coffee beans collected from exporters. The lowest percentage of samples infected by all fungi was also found on coffee beans collected from exporters.

Reducing sugar content of coffee beans collected from exporters was lower than that from farmers and traders. Aroma and flavor values tended to increase from farmers through traders to exporters, while the body decreased. Some off-flavors (i.e. earthy, mouldy, fermented and woody) were encountered in a few coffee samples from farmers as well as from traders. There was no off-flavor encountered in the coffee samples from exporters.
\end{abstract}

Key words: Stored products pests/Postharvest handling/Technology processing/Moisture content Physical quality/Insect/Fungi/Reducing sugars/Coffee cupping/Coffee/ Lampung.

\section{INTRODUCTION}

People all over the world are all facing global competitiveness. With the advent of wider market access and perceived increase in demand for farm products, we face the responsibility of maintaining the sustainability of our resources through appropriate research program in postharvest. It would minimize postharvest losses which in turn should benefit our farmers in terms of higher productivity and incomes. Food selfsufficiency can be attained by increasing production and minimizing food losses and quality degradation resulting from irjefficient postharvest handling. 
Coffee is one of the important export commodities in Indonesia. Licht (1995) reported that Indonesia is the biggest coffee producer in Asia. Based on data from the Central Bureau of Statistics (1996) between January - September 1996; Indonesia has exported 253027 tons of coffee beans. Most jf coffee beans production is derived from smallholders.

During storage, coffee beans could be infested by insects, mites, microorganisms and rodents. Insects are considered the most significant cause of losses. Among microorganisms, fungi are the most important cause of deterioration of stored products. The role of insects on fungal infection cannot be disregarded. Aside from injuring seeds, insects also serve as carriers of fungi. Furthermore, the metabolic activities of insects produce enough heat and moisture (specially during longterm storage) to allow fungal growth.

No intensive study has been carried out on the occurrence of insects and fungi on stored coffee beans in Indonesia.

The objective of this study was to get information on postharvest handling and technology processing of coffee beans at farmer, trader and exporter levels in Lampung province. The moisture content, physical quality, pest infestation (insect and fungi), reducing sugar content and coffee cupping (organoleptic test) of coffee beans were also analyzed.

\section{MATERIALS AND METHODS}

Time and location of surveys

A survey was conducted during harvest time (July 1998) in two regencies, i.e. West Lampung regency (Fajar Bulan and Sumber Jaya villages) and Tanggamus regency (Data-rajan, Air Naningan, Way Harong, Gunung Megang and Tekad villages). These regencies were selected because they produce large quantities of coffee beans.

Interviews using questionnaires

Interviews were carried out during the survey to get information on postharvest handling and technology processing of coffee beans at farmer, trader and exporter levels. The number of respondents from each level was different depending on the condition in the field during the survey. The number of respondents from farmers, traders and exporters was 22, 20 and 4, respectively. The questionnaires contained questions on postharvest handling and technology processing carried out by farmers, traders and exporters, and problems encountered by them.

Sampling methods

The number of samples taken from each level was 20. Not all samples were derived from the respondents. About $1 \mathrm{~kg}$ of each sample was taken randomly from 
farmer, trader and exporter levels. Samples of coffee (primary samples) from each stack were taken randomly from a certain number of sacks using a sampling spear. Insects were separated from each primary sample using graded sieves. Each primary sample was divided several times using a sample divider to obtain working samples for analyzing moisture content, physical quality, fungi, reducing sugars, organoleptic test and reserve sample. The presence of insects was estimated within the sacks.

\section{Moisture content analysis}

Moisture content of coffee beans (wet weight) was determined by the oven method (ISC 1992). Two replicates were used for each sample. The beans were ground and dried in the oven at $130 \pm 2^{\circ} \mathrm{C}$ for 6 hours (first period), and then they were placed in a desiccator for,a night. They were re-dried in the oven at $130 \pm 2^{\circ} \mathrm{C}$ for 4 hours (second period). The moisture content was determined using the formula:

Moisture content $=\mathrm{P},+\left[\frac{\mathrm{P}_{2}-\mathrm{P}_{1}}{2}\right]$

where : $\mathrm{P}$, is the first period moisture content (in $100 \mathrm{~g}$ of sample) ?2 is the second period moisture content (in $100 \mathrm{~g}$ of sample)

\section{Physical quality analysis}

Physical quality analysis was determined based on SN1 01-2907-1992 (ISC 1992). Quality level of coffee bean samples was determined based on the number of defective beans from $300 \mathrm{~g}$ of sample. Quality classification based on defective beans system and determination of the number of defective beans are shown in Tables 1 and 2.

Table 1. Quality classification based on defective beans system

\begin{tabular}{ll}
\hline \hline Grade & \multicolumn{1}{c}{ Criteria of grade } \\
\hline Grade 1 & Maximum number of defective beans 11 \\
Grade 2 & Number of defective beans $12-25$ \\
Grade 3 & Number of defective beans 26 - 44 \\
Grade 4-A & Number of defective beans 45-60 \\
Grade 4-B & Number of defective beans 61-80 \\
Grade 5 & Number of defective beans 81-150 \\
Grade 6 & Number of defective beans 151 - 225 \\
\hline
\end{tabular}

Notes : The number of defective beans was determined based on Table 2. 
Table 2. Determination of the number of defective coffee beans

\begin{tabular}{rll}
\hline No. & \multicolumn{1}{c}{ Kind of defective } & \multicolumn{1}{c}{ Defective value } \\
\hline 1. & 1 (one) black bean & 1 (one) \\
2. & 1 (one) a half of black bean & $1 / 2$ (a half) \\
3. & 1 (one) broken black bean & $1 / 2$ (a half) \\
4. & 1 (one) cherry bean & 1 (one) \\
5. & 1 (one) brown bean & $1 / 4$ (a quarter) \\
6. & 1 (one) big husk & 1 (one) \\
7. & 1 (one) middle husk & $1 / 2$ ( a half) \\
8. & 1 (one) small husk & $1 / 5$ (one fifth) \\
9. & 1 (one) bean with hull & $1 / 2$ ( a half) \\
10. & 1 (one) big hull & $1 / 2$ a half) \\
11. & 1 (one) middle hull & $1 / 5$ (one fifth) \\
12. & 1 (one) small hull & $1 / 10$ (one tenth) \\
13. & 1 (one) broken bean & $1 / 5$ (one fifth) \\
14. & 1 (one) immature bean & $1 / 5$ (one fifth) \\
15. & 1 (one) bean with one hole & $1 / 10$ (one tenth) \\
16. & 1 (one) bean with more than one hole & $1 / 5$ (one fifth) \\
17. & 1 (one) big branch, soil, or gravel & 5 (five) \\
18. & 1 (one) middle branch,soil, or gravel & 2 (two) \\
19. & 1 (one) small branch, soil, or gravel & 1 (one) \\
\hline
\end{tabular}

Notes : If one bean has more than one kind of defective, the defective value was determined based on the highest defective value.

\section{Insect and fungal analyses}

The insects were identified using Haines (1991) as the main reference. Fungi were isolated using direct plating method on Dichloran 18\% Glycerol Agar (DG18) (Pitt and Hocking 1997). Before plating, samples were individually disinfected using 1\% sodium hypochlorite for 1 minute. One hundred beans were then plated (10 beans/plate) on the medium and incubated at $25^{\circ} \mathrm{C}$ for 7 days. The fungi were identified using Samson et al. (1996), and Pitt and Hocking (1997) as the main references.

\section{Reducing sugars analysis}

Reducing sugars (dry weight) was determined according to Somogyi Nelson's method (McCready 1970). In alkalic condition, reducing sugars reduce $\mathrm{Cu}^{2+}$ to $\mathrm{Cu}^{+}$. Alkalies give a specific color if added with arsenicmolibdat and the absorbency of the color was measured by spectrophotometer on wave length $510 \mathrm{~nm}$. Reducing sugars was determined using standard curve and glucose as a reference. 
The occurrence of insects, fungi and organoleptic characteristics - Okky S. Dharmaputra et al.

\section{Organoleptic test analysis}

Coffee cupping was determined according to Lingle's method (1986). Coffee bean samples were roasted using Probat roaster Type PRE-2 at $200^{\circ} \mathrm{C}$ until medium roast level (color degree of \# 55 Agtron/Specialty Coffee Association of America). Roasted coffee was then ground at medium grind degree. One hundred fifty ml boiling water was added to about $10 \mathrm{~g}$ of roasted and ground coffee. The test was carried out by 4 experienced panelists on aroma, flavor, body, and defect characteristics. Evaluation for each character was determined by numerical system (scoring): 0 = none, 1 = low, 2 = low-medium, 3 = medium, $4=$ medium-high, $5=$ high, respectively.

\section{RESULTS AND DISCUSSION}

\section{Interviews with farmers, traders and exporters}

\section{a. Farmer level}

The results of the questionnaires are shown in Appendix 1. Most of the fanners (77.3\% respondents) cultivated only robusta coffee, while others (22.7\%) cultivated arabica and robusta coffee, especially in West Lampung. Determination of harvest time was based on visual observation of the color of the berry. The ripeness of coffee berry is indicated by its red color. Nevertheless, strip methods of harvesting was carried out when the number of ripe berries was about $80 \%$.

The drying process was carried out by farmers. Most of the farmers (63.6\%) dried the coffee directly without opening the berries, and consequently they stored the coffee in the form of dried coffee berries. The others (36.4\%) opened the berries using a machine before drying. The final form obtained was called green coffee. Applying this method, coffee beans would dry faster, and thus farmers could sell them faster.

The drying facilities used by farmers were varied, i.e. on the ground, on a plastic (polypropylene) sheet and on paved floor. Farmers revealed that in general there was no problem with insects as well as fungi in the storage.

\section{b. Trader level}

The results of questionnaires are shown in Appendix 2. Traders bought coffee beans from farmers, although the moisture content was still high (20-30\%). In this case, the farmers gave a discount for the undesirable moisture content of the coffee beans. Most of traders (85.7\%) further sun-dried their coffee beans for less than 1 day or only several hours. 
Traders dried coffee beans on polypropylene sheet (42.9\%) and paved floor (57.1\%). In general, traders stored the beans for not more than 2 days by spreading them on the floor in their warehouse/store (65\%) and the beans were packed using plastic bags (30\%).

Most of traders (60\%) sorted and selected the beans that will be sold to exporters, because exporters classified the price of beans based on moisture content and physical quality (i.e. percentage of extraneous matter, hulls, beans with holes and black beans).

Most of the traders did not have any problem with insects and fungi. Nevertheless, if mouldy beans were found, no action was taken by $65 \%$ of the respondents.

\section{Exporter level}

The results of questionnaires are shown in Appendix 3. Exporters in Lampung obtained coffee beans from traders in Lampung province, Java and other provinces in Sumatera. Determination of price classification was based on moisture content and physical quality of the beans. The beans were packed in jute bags (91.7\%) and plastic bags (8.3\%) before reprocessing (further dried, sorted and sifted). The duration of storage was usually less than 1 week. Further drying was carried out using a mechanical dryer up to moisture content of $12-13 \%$. Sorting was conducted using an electronic sorting machine (sortex) to discard extraneous matter and black beans. After sorting, grade quality could be determined. The beans were then packed in jute bags or containers, fumigated, and finally exported. Generally, fumigation was conducted by private companies in warehouses or in the containers depending on customer demand. The fumigant used was methyl bromide (87.5\% of respondents) or phosphine (12.5\%) depending on customer demand and importing countries.

All exporters monitored insect pest infestation. Most of them (75\%) did not have any problem with insect pests, while the others (25\%) did.

\section{Moisture content and physical quality}

Moisture content of coffee beans collected from farmers $(16.1 \pm 1.3 \%)$ and traders $(16.5 \pm 3.3 \%)$ were higher than the tolerable limit recommended by SNI (13\%). All the samples (100\%) collected from farmers has a moisture content of more than $13 \%$. Similar moisture content was obtained from $90 \%$ samples collected from traders (Table 3). Based on statistical analysis, moisture content of coffee beans from farmers was not significantly different compared to coffee beans collected from traders, but that from traders was more varied.

Moisture content of coffee bean samples from exporters (12.6 $\pm 0.5 \%)$ (Table 3) was lower compared to samples from farmers and traders, but $20 \%$ of the total samples collected from exporters still exceeded the tolerable limit recommended by SNI. Exporters re-processed the coffee from traders to meet the standard. The 
The occurrence of insects, fungi and organoleptic characteristics - Okky S. Dharmaputra et at.

Table 3. Moisture content and physical quality of coffee beans collected from farmers, traders and exporters

\begin{tabular}{llll}
\hline \hline \multicolumn{1}{c}{$\begin{array}{c}\text { Source of } \\
\text { coffee beans }\end{array}$} & Moisture content (\%) & \multicolumn{1}{c}{$\begin{array}{c}\text { Grade of quality } \\
\text { (\% samples) }\end{array}$} & $\begin{array}{c}\text { Number (\%) of sam- } \\
\text { ples with moisture } \\
\text { content }>13 \%\end{array}$ \\
\hline Farmers & $16.1 \pm 1.3 \mathrm{a}$ & $5(10), 6(90)$ & $20(100)$ \\
Traders & $16.5 \pm 3.3 \mathrm{a}$ & $6(100)$ & $18(90)$ \\
Exporters & $12.6+0.5 \mathrm{~b}$ & $\begin{array}{l}4-\mathrm{A}(10), 4-\mathrm{B}(15), \\
5(20), 6(55)\end{array}$ & $4(20)$ \\
\hline
\end{tabular}

Numbers followed by the same letter did not differ significantly according to Tukey's Test at 95\% confidence level

Notes : Grade 4-A : : samples of coffee beans with the number of defective bean 45-60

Grade 4-B : samples of coffee beans with the number of defective bean $61-80$

Grade 5 : samples of coffee beans with the number of defective bean 81 - 150

Grade 6 : samples of coffee beans with the number of defective bean 151 - 225

process included drying, mixing, grading and packaging. Exporters dried coffee beans using mechanical dryers. The temperature of the dryer was set at $200^{\circ} \mathrm{C}$ or more; consequently, the moisture content of coffee beans from farmers and traders could be decreased from $16 \%$ up to about $13 \%$ within a short period.

Based on the number of defective beans, the quality of samples from traders was not better, it even tended to be of lower quality $(100 \%$ of samples consisted of the lowest Grade 6) compared with that from farmers ( $10 \%$ of samples consisted of Grade 5 and $90 \%$ of samples consisted of Grade 6) (Table 3). Traders bought coffee beans from farmers against the price which is based on moisture content, number of defective beans and extraneous matter. Defective beans (black beans, brown beans, immature beans, broken beans and cherries) and the extraneous matter were counted arbitrarily by the traders. Most of traders possessed an electronic moisture tester (generally Cera Tester) which is used to determine the moisture content for pricing. Nevertheless, the tester had never been calibrated, thus the result of determination is unreliable. Traders mixed the coffee from farmers. As a consequence the mixing of high as well as low quality coffee resulted in downgrading.

In general, the physical quality of coffee beans from exporters was better (10\% of samples consisted of grade $4-\mathrm{A}, 15 \%$ of samples grade $4-\mathrm{B}, 20 \%$ of samples grade 5 and 55\% of samples grade 6) than that from farmers and traders (Appendix 2). Exporters sorted coffee beans obtained from traders in order to reduce the defects especially black beans and beans in cherry. The sorting process was conducted using electronic sorting machine. In addition, the coffee beans were also sieved with screens to get a uniform size and clean beans. 


\section{The presence of insects}

Haines (1991) reported that insect species associated with stored coffee beans were Araecerus fasciculatus, Hetebostrychus brwmeus and Prostepanus trunchatus.

The number of insect species found in coffee bean samples collected from farmers, traders and exporters, and the percentage of samples infested by the insects were relatively low (Table 4). Similar results were reported by the respondents.

Table 4. Insect species found on coffee beans collected from farmers, traders and exporters

Insect species

Ahasverus advena

Araecerus fasciculatus

Liposcelis bostrycophila

L. enlomophila

Sitophilus zeamais
$0 \%$ samples infested by insects

Farmers Traders Exporters

0

5

0

0

0

5

10

0

30

10

10

40

0

5

In this study, insect species found on coffee beans collected from farmers were Liposcelis bostrycophila (10\% of samples) and L. entomophila (10\%) (Table 4). This result showed that insect infestation on coffee beans from farmers was relatively low, because farmers did not store the beans for a long period. The results of interviews using questionnaires showed that only $14.3 \%$ of farmers stored coffee beans for more than 3 days (Appendix 1). Haines (1995) reported that L. entomophila was found on $50 \%$ of samples of stored coffee beans in Java and Sumatera. In a tropical country like Indonesia, the predominant psocid (insect of genera Liposcelis) found were L. bostrycophila and L. entomophila (Leong and Ho 1991;SyarifandHalid 1993).

The role of psocids is not well understood, as to whether these insects eat or cause deterioration of stored commodities. Psocids are often found in humid warehouses (Syarief and Halid 1993). According to Sidik and Cahyana (1992), high populations of Liposcelis spp. made the warehouse dirty; consequently working activities were disturbed. Recently it was found that Liposcelis spp. were real stored product pests. Their heavy infestations on stored grains occurred in Indonesia, India and Australia (Roesli et al. 1998).

The occurrence of L. bostrycophila and L. entomophila on coffee beans at the farmer level was due to the high moisture content of the beans $(16.1 \pm 1.3 \%)$ and the sanitary conditions of the storage facility which were not managed properly. In Indonesia, populations of psocids on rice have increased drastically several months after harvest (Santoso et al. 1996).

Three insect species were found on coffee beans at the trader level, namely Ahasverus advena (5\% of samples), L. entomophila (10\%) and Sitophilus zeamais 


\section{The occurrence of insects, fungi and organoleptic chaiaeteristics - Okky S. Dharmaputra et al.}

(5\%) (Table 4). In general, S. zeamais is an insect pest found on milled rice, maize and pulses. The presence of the three insect species on coffee beans was due to migration, because the beans were stored in the stores located at traditional markets which sell milled rice and maize. Ahasverus advena is a fungus feeder. Its presence was due to high moisture content of coffee beans (10.5-22.7\%). According to Haines (1991), A. advena often found on damaged and mouldy commodities in storage is an indicator of wet storage facility.

Three insect species were also found on coffee beans at the exporter level. They were Araecerus fasciculatus (5\% of samples), Liposcelis bostrycophila (30\%) and L. entomophila (40\%) (Table 4). L. bostrycophila and L. entomophila were more often found at the exporter level than at the farmer and trader levels. This was because coffee beans stored by exporters were derived from farmers and traders and infested by those insects, resulting in their presence in greater numbers on the beans at the exporter. Besides that, frequent fumigation carried out by exporters affected the population of Liposcelis spp. According to Roesli et al. (1998), improper fumigation, i.e. shorter exposure period or too low gas concentration, caused an increase in populations of these insects.

A. fasciculatus is a major pest of stored coffee beans. Its presence caused damage to the beans, thus decreasing the selling value. Haines (1991) revealed that the presence of $A$. fasciculatus on export commodities such as coffee and cocoa beans could decrease the selling value, although the damage might not be heavy. This insect was also found on stored products in Lampung and South Sumatera (Haines 1995).

\section{The presence of fungi}

Based on an interview, most of the respondents said that they had no problem with fungi. Their opinion was only based on visual observation. Nevertheless, based on fungal isolation using DG18, all beans were infected by fungi.

Fifteen fungal species were isolated on coffee beans collected from farmers. They were Aspergillus flavus , A. niger, A. ochraceus, A. penicilloides, A. tamarii, A. versicolor, A. wentii, Cladosporium cladosporioides, Eurotium amstelodami, E. chevalieri, Fusarium semitectum, Lasiodiplodia theobromae, Mucor hiemalis, Penicillium citrinum and Wallemia sebi. A. niger was the dominant fungus isolated, having been found in $100 \%$ of all samples, and $83.5 \%$ of all beans examined. $A$. flavus was the next most common fungus, being present in $90 \%$ of the samples, but only $12.3 \%$ of all beans examined. P. citrinum was present in only $15 \%$ of the samples and infected $18.7 \%$ of all beans examined (Table 5).

Ten fungal species were isolated on coffee beans collected from traders. They were A. flavus, A. niger, A. ochraceus, A. penicilloides, A. tamarii, A. versicolor, A. wentii, E. chevalieri, L. theobromae and $P$. citrinum. A. niger was also the dominant fungus isolated, being found in $100 \%$ of the samples, and $94.9 \%$ of all beans 
BIOTROPIA No. 14, 1999

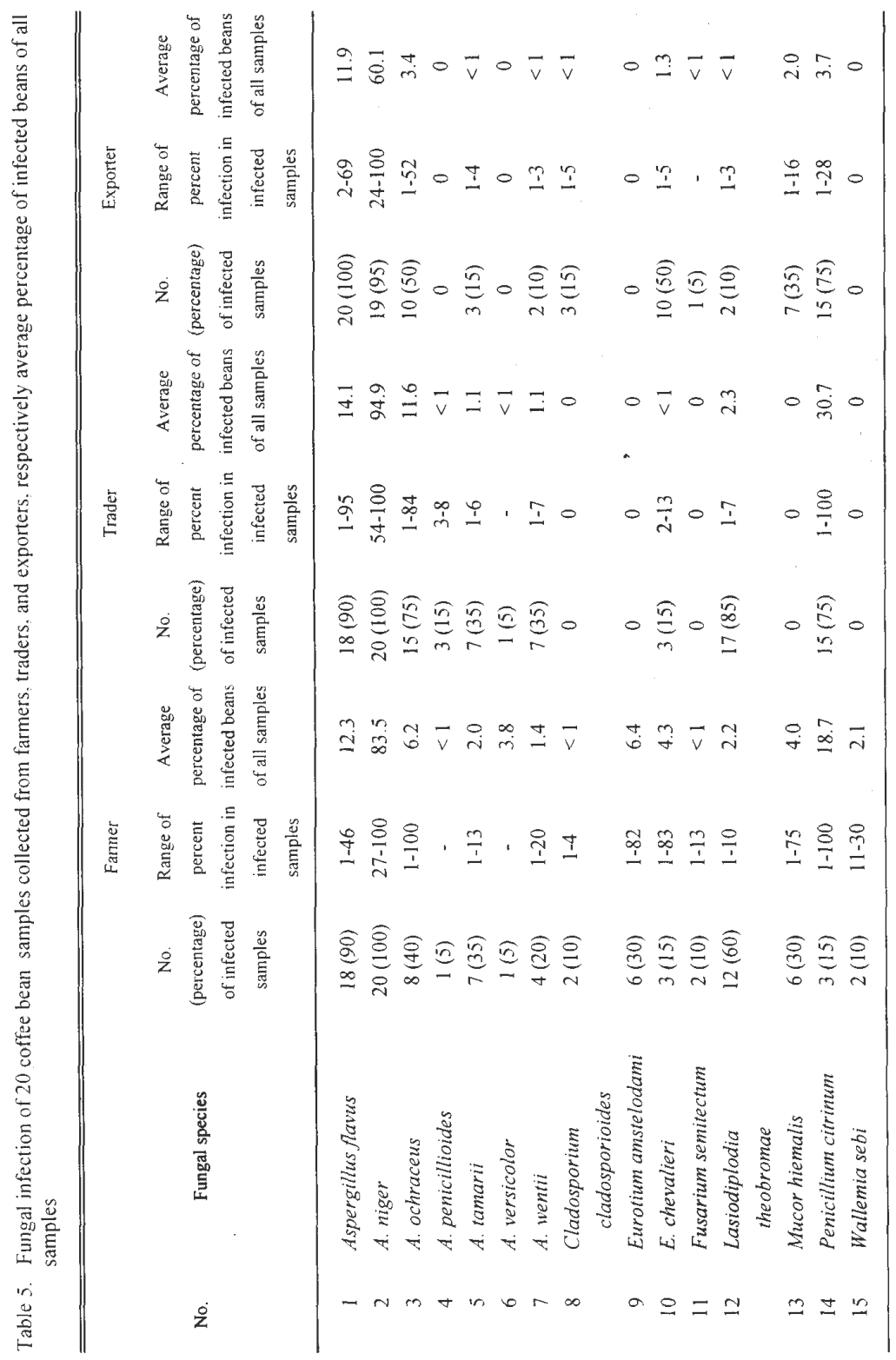


The occurrence of insects, fungi and organoleptic characteristics - Okky S. Dharmaputra et al.

examined. A. flcrvus, A. ochraceus, $L$. theobromae and $P$. citrinum were all present in more than $75 \%$ of the samples, but their infection on all beans examined were relatively low (14.1, 11.6, 2.3 and 30.7\%, respectively) (Table 5).

Eleven fungal species were isolated on coffee beans collected from exporters. They were A. flavus , A. niger, A. ochraceus, A. tamarii, A. wentii, C. cladosporioi-des, E. chevalieri, F. semitectum, $L$. theobromae, $M$. hiemalis and $P$. citrinum. The most commonly occurring species was A. niger, present in $95 \%$ of samples, and $60.1 \%$ of all beans examined. A. flavus and P. citrinum were found in 100 and $75 \%$ of samples, respectively, but infected only 11.9 and $3.7 \%$, respectively, of all beans examined (Table 5).

According to Scott (1994) and Ono et al. (1995) A. niger and A. ochraceus could produce ochratoxin A. This toxin caused a swelling of the kidneys (nephropathy) in domestic livestock and poultry, and it has been considered as the causative agent responsible for human endemic nephropathy prevalent in areas of the Balkan countries (Prelusky et al. 1994) and Tunisia (CCFAC 1998).

Among the three levels, the number of fungal species isolated from coffee beans at the farmers level was the highest, because moisture content of all sample was more than $13 \%$ (Table 3). The dominant fungus isolated at the three levels was the same, i.e. A. niger, but the lowest infection of all beans examined among the three levels was found at exporter level, because the exporters further dried and sorted coffee beans obtained from farmers and traders. Moreover, among the three levels the lowest percentage of samples infected by all fungi was obtained from the exporter level (70.7\%), while that at farmer and trader levels were not significantly different to each other (99.1 and 99.0\%, respectively) (Table 6). Nakajima et al. (1997) reported that the dominant fungus isolated on coffee beans was A. niger.

Table 6. Percentage of samples infected by all fungi on coffee beans collected from farmers, traders and exporters

\begin{tabular}{cc}
\hline \hline Source of coffee beans & Samples infected by all fungal species (\%) \\
\hline Farmers' & $99.1 \mathrm{a}$ \\
Traders & $99.0 \mathrm{a}$ \\
Exporters & $70.7 \mathrm{~b}$ \\
\hline
\end{tabular}

Numbers followed by the same letter did not differ significantly according to Tukey's Test at 95\% confidence level

\section{Reducing sugar content}

Sugars are important components in the formation of flavor, color/pigment, caramelization and condensation products of roasted coffee. The major free sugar in coffee beans is sucrose, which reaches $6.1 \%$ in arabica coffee and $3.4 \%$ in robusta 
coffee (Trugo 1985). Besides sucrose, coffee beans also contain simple sugars including reducing ones, but in small amounts. Fructose and glucose in arabica coffee constitute $0.030-0.038 \%$ and $0.023-0.030 \%$, respectively, while in robusta coffee $0.16-0.18 \%$ and $0.19-0.21 \%$, respectively. Reducing sugars in arabica and robusta coffees are only 0.1 and $0.5 \%$, respectively (Trugo 1985).

Analysis of reducing sugars in the samples resulted in $2.7 \pm 0.3 \%$ for coffee from farmers, $3.2 \pm 0.6 \%$ for coffee from traders, and $2.3 \pm 0.2 \%$ for coffee from exporters (Table 7). Those results were higher than the reported data. Coffee beans from exporters had the lowest value compared to the coffee from farmers and traders. Those lower values were probably due to the coffee that had been further dried at quite high temperature, a condition which makes the sugars caramelized or condensed through the Maillard reaction, hence the amount was reduced. According to Winarno (1991) caramelization of sucrose occurred when the temperature is higher than the melting point $\left(160^{\circ} \mathrm{C}\right)$; the Maillard reaction is a reaction among carbohydrates, especially of reducing sugars with primary amine groups yielding pleasant brown compounds.

Table 7. Reducing sugar contents of coffee beans collected from farmers, traders and exporters

\begin{tabular}{lc}
\hline \hline Source of coffee beans & Reducing sugar content (\%) \\
\hline Farmers & $2.7 \pm 0.3 \mathrm{~b}$ \\
Traders & $3.2 \pm 0.6 \mathrm{a}$ \\
Exporters & $2.3 \pm 0.2 \mathrm{c}$ \\
\hline
\end{tabular}

Numbers followed by the same letter did not differ significantly according to Tukey's Test at 95\% confidence level

\section{Coffee cupping (organoleptic test)}

Aroma and flavor characters of all coffee samples were termed as low-medium to medium, while their body character ranged from medium to full (Table 8). Coffee from Lampung is known for its unique taste with full bodied and unclean flavor. The unclean flavor is also frequently found in dry processed coffee beans. Some very low off-flavors like earthy, musty, and mouldy shadowing the coffee flavor resulted in a unique character.

Aroma and flavor values tended to increase for the coffee at farmer $(2.4+0.4$ and $2.5+0.5$, respectively), trader ( $2.8 \pm 0.3$ and $2.6 \pm 0.3$, respectively), and exporter levels ( $2.9 \pm 0.1$ and $2.9+0.2$, respectively), while the body decreased with values of $4.3 \pm 0.5,3.6 \pm 0.2$, and $3.6 \pm 0.2$ for each coffee origin (Table 8 ). The aromatic characters of coffee beans from exporters was the strongest, it was probably due to caramelization during the drying process which further produced specific aroma. 
The occurrence of insects, fungi and organoleptic characteristics - Okky S. Dharmaputra etal.

TableS. Results of coffee cupping (organoleptic test) on coffee beans collected from farmers, traders and exporters

\begin{tabular}{|c|c|c|c|c|}
\hline $\begin{array}{c}\text { Source of } \\
\text { coffee beans }\end{array}$ & Aroma & Flavor & Body & $\begin{array}{c}\text { Off-flavor } \\
\text { (\% of samples) }\end{array}$ \\
\hline Farmers & $2.4 \pm 0.4$ & $2.5 \pm 0.5$ & $4.3 \pm 0.5$ & Earthy \\
\hline & & & & $\begin{array}{l}\text { Mouldy : } 5 \\
\text { Fermented : } 5\end{array}$ \\
\hline Traders & $2.8+0.3$ & $2.6+0.3$ & $3.6+0.2$ & $\begin{array}{l}\text { Earthy }: 35 \\
\text { Woody }: 5\end{array}$ \\
\hline Exporters & $2.9 \pm 0.1$ & $2.9 \pm 0.2$ & $3.6+0.2$ & - \\
\hline
\end{tabular}

Score: 0 = none, 1 = low, 2 = low-medium, 3 = medium, 4 = medium-high, 5 = high

Some off-flavors were encountered from few coffee samples from farmers as well as from traders, i.e. earthy (35\% of samples), mouldy (5\% of samples), fermented (5\%), and woody (5\%). There was no off-flavor encountered in the coffee samples from exporters. It was due to the mixing of defective beans with good beans that the off-flavor characters decreased and could not be detected by the panelists.

The soil odor was absorbed by fat in the beans causing an earthy flavor. The off-flavor was also caused by fungal infection, since some fungi could produce chemical compounds with earthy flavor, like 2-methylisoborneol and geosmin. The earthy off-flavor was higher in samples collected from farmers, since most farmers dried their coffee beans on the ground with no underlayer or mat used. This made the coffee cherry become dirty and the beans were covered with soil dust after de-hulling. Drying of coffee directly on the ground takes a longer time, since the moist ground hampers evaporation. It makes the coffee mouldy and tainted with the earthy and mouldy characters. The off-flavor could be avoided if the drying process was conducted on a sheet or mat, or on patio made of concrete. Sanitation along with the drying process should be emphasized, since the dirty coffee would be infected by fungi.

Mouldy off-flavor is also referred to as musty, which is an odor taint giving the coffee beans a mouldy odor, a result of fats in the coffee beans absorbing organic material from fungi during the drying process. This off-flavor is more pronounced than the earthy off-flavor. The defect may also appear during storage, if the coffee beans had not been dried properly. If the coffee beans from farmers and traders had a high moisture content ( $\pm 16 \%$ ), it could be easily infected by fungi, especially the toxigenic fungi (see fungal analysis). Once the taint occurred, it would remain permanently. In order to avoid this defect, it is suggested that the coffee be dried at the very early stage of production (on the farm) properly, and the process be continued until the moisture content reaches below 13\%. It is advisable not to store the coffee beans with high moisture contents. 
Fermented off-flavor is an undesirable taste in the coffee beans that produces a strong unpleasant sour sensation or sting on the tongue. This defect is caused by the coffee cherries that had been kept or heaped for days, thus making sugars in the beans fermented and produce sour substances. Fresh cherries could be easily fermented, especially the pulp and mucilage parts. The increase in temperature and microorganisms present in the cherries will hasten the fermentation. The sour substances produced would be absorbed into the beans and taint the coffee. In order to avoid this defect, the fresh cherries had to be processed immediately. The fresh cherries should be dried on the patio soon after harvest. During the drying process, the cherries were frequently turned upside-down to hasten the process and to get more uniformly dried beans. Re-wetting by the rain should also be avoided.

No off-flavor was encountered in the coffee samples from exporters which showed quality improvement of the coffee beans collected from farmers and traders after being re-processed. The improvement was due to fuijher drying, sorting out of bad beans, and mixing of coffee lots. The mixing of perfect and defective coffee beans could neutralize or dilute the off-flavor which makes the percentage of off-flavor beans present become very low and undetectable by panelists.

\section{CONCLUSIONS}

Most farmers cultivated robusta coffee and they carried out the drying process to obtain commercial coffee beans. Postharvest handling and technology processing methods became better from farmers to exporters. Physical quality, pest infestation (insect and fungi), moisture content, reducing sugar content and coffee cupping of coffee beans also became better from farmers to exoorters.

\section{RECOMMENDATIONS}

Extension and dissemination of good handling practices for coffee beans especially at farmer and trader levels are necessary to improve the coffee postharvest handling and technology processing.

\section{ACKNOWLEDGMENT}

The authors gratefully acknowledge the financial support of the Government of Indonesia. Thanks are due to the Plantation Office Province Level, Lampung and Association of Indonesian Coffee Exporters, Bandar Lampung, for their information and cooperation during the surveys at farmer, trader and exporter levels in Lampung. The authors are also grateful to the Indonesian Research Institute for Coffee and Cocoa, for their collaboration in this study. 
The occurrence of insects, fungi and organoleptic characteristics - Okky S. Dharmaputra etal.

\section{REFERENCES}

Central Bureau of Statistics. 1996. Summary Bulletin of CBS. Jakarta.

CCFAC. 1998. Revised position paper on ochratoxin A. Paper presented at the 30"' Session of the Codex Committee on Food Additives and Contaminants. The Hague, The Netherlands, 9-13 March 1998.

Haines, C.P. 1991. Insects and arachnids of tropical stored products, their biology and identification (A Training Manual). Natural Resources Institute, UK.

Haines, C.P. 1995. Insects and arachnids in Indonesian food stores-biodiversity in a man-made environment. Proceedings of the Symposium on Pest Management for Stored Food and Feed, Bogor, Indonesia, 5-7 September 1995. p: 95 - 125.

Indonesian Standardization Council. 1992. Indonesian National Standard. SNI 01-2907-1992. Coffee.

Leong, E.C.W. and S.H, Ho. 1991. Research on Liposcelis bostrycophilus and Liposcelis entomophilus (Psocoptera: Liposcelidae). In J.O. Naewbanij and A.A. Manilay (eds.). Proceedings of the 14"' ASEAN Seminar on Grain Postharvest Technology, 5-8 November 1991, Metro Manila, Philippines, p: 317-327.

Licht, P.O. 1995. International Coffee Yearbook. World Coffee Production.

Lingle, T.R. 1986. The Coffee Cupper's Handbook: A Systematic Guide to Sensory Evaluation of Coffee's Flavor. Coffee Dev. Group, Washington D.C.

McCready, R.M. 1970. Monosaccharides. In M.A. Joslyn (ed.). Methods in Food Analysis Physical, Chemical and Instrumental Methods of Analysis, 2' ${ }^{\text {nd }}$ ed. Academic Press, New York. p. 475 - 509.

Nakajima, M., H. Tsubouchi, M. Miyabe, and Y. Ueno. 1997. Survey of aflatoxin BI and ochratoxin A in commercial green coffee beans by high-performance liquid chromatography linked with immunoaffinity chromatography. Food and Agricultural Immunology (9): 77 - 83.

Ono, H., A. Kataoka, M. Koakutsu, K. Tanaka, S. Kawasugi, M. Wakazawa, Y. Ueno and M. Manabe. 1995. Ochratoxin A producibility by strains of Aspergiltus niger group stored in IFO culture collection. Mycotoxins (41): 47 - 51 .

Pitt, J.I. and A.D. Hocking. 1997. Fungi and Food Spoilage. Blackie Academic and Professional Publ.,London.

Prelusky, D.B., B.A. Rotter and R.G. Rotter. 1994. Toxicology of mycotoxins. In J.D. Miller and H.L. Trenholm (eds.). Mycotoxins in Grains; Compounds other than Aflatoxin. Eagan Press, St. Paul, Minnesota, p. 359- 403.

Roesli, R., R. Jones and D.P. Rees. 1998. Factors affecting outbreaks of Liposcelis (Psocoptera: Liposcelidae) population in grain storage. Paper presented at the $7^{\text {"' International Working }}$ Conference on Stored-Product Protection, Beijing, China, 14-19 October 1998.

Samson, R.A., E.S. Hoekstra, J.C. Frisvad and O. Filtenborg. 1996. Introduction to Food-Borne Fungi. 3th ed. Centraalbureau voor Schimmelcultures, Baam, The Netherlands.

Santoso, T, Sunjaya, O.S. Dharmaputra, H. Halid and R.J. Hodges. 1996. Pest management of psocids in milled rice stores in humid tropics. International journal of Pest Management, 42 (3): 189 - 197.

Scott, P.M. 1994. Penicillium and Aspergillus Toxins. In J.D. Miller and H.L. Trenholm (eds.). Mycotoxins in Grain: Compounds other than Aflatoxin. Eagan Press, St. Paul. p. 261 -285.

Sidik, M. and Y. Cahyana» 1992. Storage pest problem and its management in Indonesia. BIOTROP Special Publication, (45): 75 - 87.

Syarif, R. and H. Halid. 1993. Teknologi Penyimpanan Pangan. Penerbit ARCAN, Jakarta.

Trugo, L.C. 1985. Carbohydrates. In R.J. Clarke and R. Macrae (eds.). Coffee Volume 1: Chemistry. Elsevier Applied Science Publ. London, p: 83 - 114.

Winarno, F.G. 1991. Kimia Pangan dan Gizi. PT. Gramedia Pustaka Utama, Jakarta. 
Appendix 1. Results of questionnaires on postharvest handing and technology processing of coffee beans at farmer level

\begin{tabular}{|c|c|c|}
\hline No. & Subject & \% respondents \\
\hline \multirow[t]{4}{*}{1.} & Type of coffee cultivated: & \\
\hline & a. robusta coffee (Coffea robusta) & 77.3 \\
\hline & b. arabica coffee (C. arabica) & 0 \\
\hline & c. both types of coffee & 22.7 \\
\hline \multirow[t]{4}{*}{2.} & Determination of harvest time was based on: & \\
\hline & a. color of coffee berry & 100 \\
\hline & b. size of coffee berry & 0 \\
\hline & c. others & 0 \\
\hline \multirow[t]{3}{*}{3.} & Harvesting method of coffee berries: & \\
\hline & a. selected method & 9.1 \\
\hline & b. strip method & 90.9 \\
\hline \multirow[t]{4}{*}{4.} & Duration of storing coffee berries: & \\
\hline & a. $<1$ day & 0.0 \\
\hline & b. 1-3 days & 35.7 \\
\hline & c. $>3$ days & 14.3 \\
\hline \multirow[t]{4}{*}{5.} & Storing method of coffee berries: & \\
\hline & a. in bag & 100 \\
\hline & b. in another container & 0 \\
\hline & c. spreading out on the floor & 0 \\
\hline \multirow[t]{3}{*}{6.} & Opening of coffee berry before drying: & \\
\hline & a. yes & 36.4 \\
\hline & b. no & 63.6 \\
\hline \multirow[t]{5}{*}{7.} & Drying facilities: & \\
\hline & a. ground & 0.0 \\
\hline & b. plastic (polypropylene) & 27.3 \\
\hline & c. paved floor & 22.7 \\
\hline & d. other & 0 \\
\hline \multirow[t]{4}{*}{8.} & Duration of drying: & \\
\hline & a. $<1$ week & 31.8 \\
\hline & b. $1-2$ weeks & 59.1 \\
\hline & c. $>2$ weeks & 9.1 \\
\hline \multirow[t]{3}{*}{9.} & Methods for determining dried coffee beans: & \\
\hline & a. experience/organoleptic & 100 \\
\hline & b. using equipment for measuring moisture content & 0 \\
\hline \multirow[t]{3}{*}{10.} & Type of stored coffee beans: & \\
\hline & a. dried coffee berries & 63.6 \\
\hline & b. green coffee & 36.4 \\
\hline \multirow[t]{4}{*}{11.} & Duration of storing coffee beans: & \\
\hline & a. $<1$ week & 95.4 \\
\hline & b. $1-2$ weeks & 4.6 \\
\hline & c. $>2$ weeks & 0 \\
\hline \multirow[t]{5}{*}{12.} & Type of bag used for storing coffee beans: & \\
\hline & a. jute bag & 4.6 \\
\hline & b. plastic bag (polypropylene) & 86.4 \\
\hline & c. others " & 0 \\
\hline & d. spreading out on the floor & 90 \\
\hline
\end{tabular}


The occurrence of insects, fungi and organoleptic characteristics - Okky S. Dharmaputra etal.

Appendix 1. (continued)

\begin{tabular}{|c|c|c|}
\hline No. & Subject & \% respondents \\
\hline \multirow[t]{4}{*}{13.} & Postharvest problems: & \\
\hline & a. pest infestation (insects and/fungi) & 18.2 \\
\hline & b. processing facility & 0 \\
\hline & c. none & 81.8 \\
\hline \multirow[t]{3}{*}{14.} & Mouldy beans problems: & \\
\hline & a. yes & 27.3 \\
\hline & b. no & 2.7 \\
\hline \multirow[t]{3}{*}{15.} & Information on postharvest of coffee: & \\
\hline & a. yes & 77.3 \\
\hline & b. no & 22.7 \\
\hline
\end{tabular}

Number of respondents: 22

Appendix 2. Results of questionnaires on postharvest handing and technology processing of coffee beans at farmer level

\begin{tabular}{|c|c|c|}
\hline 'No. & Subject & \%respondents \\
\hline \multirow[t]{6}{*}{1.} & Moisture content of coffee beans bought from farmers: & \\
\hline & a. $<12 \%$ & 0 \\
\hline & b. $12-15 \%$ & 0 \\
\hline & c. $15-20 \%$ & 0 \\
\hline & d. $20-30 \%$ & 100 \\
\hline & e. $>30 \%$ & 0 \\
\hline \multirow[t]{3}{*}{2.} & Methods for determining moisture content of coffee beans & \\
\hline & a. using equipment (Cera tester) & 75.0 \\
\hline & b. by estimating (organoleptic) & 25.0 \\
\hline \multirow[t]{5}{*}{3.} & Price classification of coffee beans based on: & \\
\hline & a. moisture content & 40.0 \\
\hline & b. moisture content and physical quality . & 60.0 \\
\hline & c. other criteria & 0 \\
\hline & d. no classification & 0 \\
\hline \multirow[t]{3}{*}{4.} & Drying method used: & \\
\hline & a. sun-drying & 93.3 \\
\hline & b. mechanical drying & 6.7 \\
\hline \multirow[t]{4}{*}{5.} & Drying facilities used: & \\
\hline & a. ground & 0 \\
\hline & b. plastic (polypropylene) & 42.9 \\
\hline & c. paved floor & 57.1 \\
\hline \multirow[t]{4}{*}{6.} & Duration of further drying: & \\
\hline & a. $<1$ day & 85.6 \\
\hline & b. $1-2$ days & 7.2 \\
\hline & c. $>2$ days & 7.2 \\
\hline \multirow[t]{4}{*}{7.} & Storing method of coffee beans: & \\
\hline & a. packed in jute bag & 5.0 \\
\hline & b. packed in plastic bag (polypropylene) 30.0 & \\
\hline & c. spreading the coffee beans on the floor 65.0 & \\
\hline
\end{tabular}


BIOTROPIA No. 14, 1999

Appendix 2. (continued)

\begin{tabular}{rlr}
\hline \hline No. & \multicolumn{1}{c}{ Subject } & \% respondents \\
\hline 8. & Duration of storing coffee beans in warehouse/store: & \\
& a. 1 -2 days & 70.0 \\
& b. 2 days -1 week & 30.0 \\
& c. $>$ 1 week & 0 \\
9. & Action conducted when mouldy beans were found: & 35.0 \\
& a. further dried & 65.0 \\
10. & b. no action & 10.0 \\
& Pest problems encountered: & 0 \\
& a. insects infestation & 90.0 \\
\hline
\end{tabular}

Number of respondents: 20

Appendix 3. Results of questionnaires on postharverst handing and technology proccesing of coffe beans at fanner level

\begin{tabular}{|c|c|c|}
\hline No. & Subject & $\%$ respondents \\
\hline \multirow[t]{3}{*}{1.} & Price classification of coffee beans based on: & 0 \\
\hline & b. moisture content and physical quality & 100 \\
\hline & c. no classification & 0 \\
\hline \multirow[t]{3}{*}{2.} & Further dried coffee beans obtained from traders: & \\
\hline & a. yes & 100 \\
\hline & b. no & 0 \\
\hline \multirow[t]{3}{*}{3.} & Drying method used: & \\
\hline & a. sun-drying & 0 \\
\hline & b. mechanical dryer (oven/mason dryer) & 100 \\
\hline \multirow[t]{3}{*}{4.} & $\begin{array}{l}\text { Moisture content of coffee beans after further dried: } \\
\text { a. }<12 \%\end{array}$ & 0 \\
\hline & b. $12-13 \%$ & 100 \\
\hline & c. $>13 \%$ & 0 \\
\hline \multirow[t]{2}{*}{5.} & Sorting coffee beans used: & \\
\hline & $\begin{array}{l}\text { a. manpower/manually } \\
\text { b. electronic sorting machine (model sortex) }\end{array}$ & $\begin{array}{r}0 \\
100\end{array}$ \\
\hline 6. & $\begin{array}{l}\text { Type of bag used for storing coffee beans before reprocessing: } \\
\text { a. jute bag } \\
\text { b. plastic bag (polypropylene) } \\
\text { c. bulk system }\end{array}$ & $\begin{array}{r}91.7 \\
8.3 \\
0\end{array}$ \\
\hline 7. & $\begin{array}{l}\text { Duration of storing coffee beans in warehouse/factory: } \\
\text { a. }<1 \text { week } \\
\text { b. } 1-4 \text { weeks } \\
\text { c. }>4 \text { weeks }\end{array}$ & $\begin{array}{r}100 \\
0 \\
0\end{array}$ \\
\hline 8. & $\begin{array}{l}\text { Pest monitoring: } \\
\text { a. yes } \\
\text { b. no } \\
0\end{array}$ & 100 \\
\hline
\end{tabular}


The occurrence of insects, fungi and organoleptic characteristics - Okky S. Dharmaputra etal.

Appendix 3. (continued)

\begin{tabular}{rlr}
\hline \hline No. & \multicolumn{1}{c}{ Subject } & \% respondents \\
\hline \multirow{2}{*}{9.} & Fumigation of coffee beans before exported: & \\
& a. yes & 10 \\
10. & b. no & 0 \\
& Type of fumigant used: & 125 \\
& a. phosphine & 87.5 \\
11. & b. methyl bromide & \\
& Fumigation was carried out by: & 0 \\
& a. the exporters & 100 \\
12. & b. private companies & 25.0 \\
& Fumigation site: & 75.0 \\
& a. warehousee & 25.0 \\
13. & b. container & 0 \\
& Pest problems encountered: & 0 \\
& a. insects infestation * & 75.0 \\
& b. fungal infection & 25.0 \\
& c. rat infestation/others & 0 \\
d. none & Complaint from importing countries: & 0 \\
& a. coffee beans were infested by insects & 0 \\
& b. coffee beans were infected by fungi & 75.0 \\
\hline
\end{tabular}

Number of respondents: 4 